\title{
Envolvimento parental no contexto de escolas públicas diferenciadas: uma análise dos contextos de ação
}

\author{
Parental involvement in differentiated public schools: an \\ analysis of the contexts of action
}

\author{
Participación parental en el contexto de escuelas públicas \\ diferenciadas: un análisis de los contextos de acción
}

\section{Harlon Romariz Rabelo Santos}

ORCID: 0000-0002-5642-0448

Mestre em Sociologia pela Universidade Federal do Ceará. Doutorando em Sociologia pelo PPGS da Universidade Federal do Rio Grande do Sul. Bolsista CAPES. E-mail: harlon.romariz@ gmail.com

\section{Resumo}

Analisam-se aqui quatro casos de envolvimento parental, pesquisados em escolas públicas diferenciadas no Ceará. Casos oriundos de uma pesquisa com estudantes de ensino médio e seus pais, de duas das Escolas Estaduais de Educação Profissional (EEEP), em 2016. Análise é feita por meio da sociologia disposicionalista de Bernard Lahire, que foca nas ações e práticas dos indivíduos a partir da noção de esquemas disposicionais, contextos e lógicas de ação. Perspectiva que enfrenta a tensão entre o passado incorporado e o presente da ação. Os dados e a análise permitem reconhecer quadros contextuais externos que mobilizam ou inibem esquemas disposicionais incorporados, especificamente, em relação ao maior ou menor envolvimento parental entre pais de diferentes capitais socioeconômicos e culturais.

Palavras-chave: Envolvimento parental; escolha escolar; escolas diferenciadas; sociologia da educação. 


\section{Introdução}

A relação família-escola tem ganhado espaço no campo da sociologia da educação. Os processos de modernização e diferenciação social tem modificado a forma como se estabelecem as ações entre a instituição escolar, seu sistema e as famílias. A universalização da oferta escolar, o crescimento das classes médias, os processos de diferenciação curricular, o acirramento competitivo pelos recursos materiais e simbólicos na sociedade contemporânea, entre outras mudanças, são fatores que interferem nessa relação, e, como aponta Maria Alice Nogueira $(2005,2011)$, acabam por despertar o interesse entre os que estudam a educação a partir da sociologia.

As mudanças na sociedade, bem como os avanços teóricos, acabam por ter implicação na configuração metodológica e nos interesses de pesquisa. No campo da sociologia da educação, vários paradigmas interpretativos concorreram para compreender os processos educacionais e a instituição escolar. Esses paradigmas, como aponta Anne Haecht (2008), são, ao fundo, perspectivas sociológicas de interpretação da ação e das práticas dos indivíduos, que, seja pelo passado incorporado, seja pela capacidade estratégica e reflexiva, acabam por impactar esse universo educacional e nos objetivos da escola. Haecht (2008) apresenta um panorama dessas perspectivas sociológicas que se resumem, em geral, a três formas de compreensão sobre as ações dos indivíduos. Uma primeira, que tem a teoria do habitus como uma chave interpretativa para compreensão da reprodução das desigualdades sociais. Em concorrência a isso, há a perspectiva da teoria do ator racional que foca na capacidade dos agentes de calcular os melhores benefícios com menores custos. Por fim, a perspectiva fenomenológica, que compreende os sujeitos ante suas interações sociais significativas e que se constituem como processos de socialização, primárias ou secundárias. Cada uma dessas perspectivas imprime uma visão e conclusões sobre a escola, seus atores e os processos educacionais.

A sociologia da educação, bem como outros campos de estudo da sociologia, depende das perspectivas sociológicas gerais, e essas perspectivas são dinâmicas e não ignoram as mudanças sociais e as novas constatações empíricas. Esse processo acaba por se constituir num contínuo refinamento teórico e empírico, produtivo para a compreensão do mundo social. Dentro desse empreendimento sociológico maior, de tentativa de compreensão das ações e práticas dos indivíduos, há alguns projetos teóricos que se constituem a partir da tensão entre essas perspectivas concorrentes. O projeto de Bernard Lahire por uma sociologia disposicionalista aparece aqui como um recente fôlego teórico, que busca, inclusive com 
objetos da sociologia da educação, analisar as ações dos indivíduos a partir de seus esquemas disposicionais incorporados, sem desconsiderar as variações contextuais do presente da ação.

Analisar o envolvimento parental é compreender os processos de escolha da escola e as atitudes dos pais em prol da vida escolar dos seus filhos. Nas sociedades modernas, onde o capital escolar é condição para o exercício da vida produtiva e civil, existe uma demanda por envolvimento dos pais e uma exigência sobre as famílias em torno desse compromisso educativo e social. Sociologicamente, analisar o envolvimento parental é analisar as ações e práticas desses pais e responsáveis, e, a partir da perspectiva disposicionalista, explicar essas ações por meio dos patrimônios disposicionais desses indivíduos que operam em lógicas de ações diferenciadas e na relação com contextos de ações singulares.

A proposta desse artigo é analisar, sobretudo como exercício teórico, casos de envolvimento parental em contextos de escolas públicas diferenciadas, especificamente, no contexto das Escolas Estaduais de Educação Profissional do Ceará. São escolas de turno integral, que articulam o ensino médio regular à formação profissional, que tem um percentual maior de egressos no ensino superior (Ceará, 2014), que figuram positivamente entre as demais escolas cearenses, tanto em termos de desempenho em avaliações externas, quanto em termos de reputação social. Adota-se aqui o termo escolas diferenciadas, inspirado em Márcio da Costa (2008), que o usa para se referir a escolas que ampliam as chances competitivas de seus egressos, mas que têm um acesso mais restrito que as demais escolas pares. Utiliza-se de dados dessa pesquisa (Santos, 2017) para, de um modo ensaiado, ter uma alternativa interpretativa do processo de envolvimento parental, a partir de um enfoque contextual, oriundo da perspectiva teórica de Lahire (2002; 2004).

Essa ideia de escolas diferenciadas se efetiva como uma categoria contextual e relativa, que se faz ante a compreensão de que existe um quase-mercado escolar na rede pública de ensino (Costa, 2010). Como apresentam Costa e Koslinski (2011) e Rosistolato (2015), apesar da parcial liberdade de escolha escolar por parte das famílias, há uma clara competição por escolas públicas diferenciadas, que ocorre por diversos motivos e de inúmeras maneiras por parte daqueles - atores familiares - que julgam estar buscando as melhores oportunidades escolares para seus filhos.

\section{Considerações teóricas: contextos e a ação/prática como objeto sociológico}

Dubet e Martuccelli (1997:245) atentam para o que eles chamam de "duas versões cruzadas da socialização”. De um lado estariam as perspectivas que constroem um indivíduo 
mais autônomo e reflexivo. Aqui estariam as perspectivas do ator racional, da fenomenologia e algumas teorias psicológicas. A outra versão é aquela bem representada por Bourdieu (2002; Bourdieu; Passeron, 2012), que foca nas estruturas e na reprodução social. Os projetos intelectuais de Lahire (2002) e Dubet (1996) tentam articular essas versões aparentemente opostas. As perspectivas teóricas desses sociólogos - esquemas disposicionais e experiência social - são resultados desse empreendimento que busca salvar teoricamente aquela sociologia que se arvora na interpretação e explicação das ações dos indivíduos, a sociologia da ação e das práticas. Para eles, o indivíduo é, ao mesmo tempo, "pessoa" e "papel”; uma unidade que imbrica "percursos individuais e processos coletivos" (Dubet; Martucceli, 1997:246).

Bernard Lahire (2002) estabelece a sua perspectiva do ator plural ao criticar o pressuposto da unicidade disposicional, presente na teoria bourdieusiana do habitus e dos campos. A pluralidade disposicional estaria tanto na formação plural dos indivíduos, quanto na pluralidade dos contextos de ações. Para Lahire (2002:36) o indivíduo é "o produto da experiência - amiúde precoce - de socialização em contextos sociais múltiplos e heterogêneos. No curso de sua trajetória [...] participou de universos sociais variados, ocupando aí posições diferentes". No entanto, tão importante quanto a multiplicidade do passado presente, é a importância da pluralidade do presente da ação:

\begin{abstract}
Os repertórios de esquemas de ação (de hábitos) são conjunto de sínteses de experiências sociais que foram construídas/incorporadas durante a socialização anterior nos âmbitos sociais limitados/delimitados, e aquilo que cada ator adquire progressivamente e mais ou menos completamente são tanto hábitos como sentidos da pertença contextual (relativa) de terem sido postos em prática. Aprende/compreende que aquilo que se faz e se diz em tal contexto não se faz e se diz em outro contexto. Este sentido das situações é mais ou menos 'corretamente' incorporado (depende da variedade dos contextos encontrados pelo ator em seu percurso e das sanções - positivas e negativas - mais ou menos precoces que lhe foram dirigidas para indicar os limites amiúde imprecisos que não devem ser ultrapassados). Para seguir até o fim a metáfora do estoque, poder-se-ia dizer que o estoque é composto de produtos (os esquemas de ação) que não são todos necessários em todo momento e em todo contexto. Depositados (deponere) no estoque, estão disponíveis, à disposição, na medida em que se pode dispor (disponere) dele. Estes produtos (da socialização) destinam-se muitas vezes a usos diferentes, postos temporária e duravelmente em reserva, à espera dos desencadeadores de sua mobilização. Enfim, as transferências e transposições (analógicas) dos esquemas de ação são raramente transversais ao conjunto dos contextos sociais, mas efetuam-se no interior dos limites - imprecisos - de cada contexto social (e, portanto, de cada repertório) (Lahire, 2002:37 [Grifo do autor]).
\end{abstract}

Dessa forma, Bernard Lahire pontua a complexidade da formação disposicional e da própria ação, tendo em vista a variabilidade contextual. Os contextos na relação com o passado disposicional provocam situações de ação que desencadeiam um certo modo de agir, 
ativado por um determinado conjunto disposicional. Dessa forma, o contemporâneo sociólogo francês propõe uma análise dos determinantes da ação que ultrapasse as perspectivas da socialização que ora dão muita ênfase ao passado, ora aos momentos da interação presente. Ele pontua:

\begin{abstract}
Pode-se distinguir duas grandes tendências entre teorias da ação e do ator. De um lado, estão os modelos que conferem um peso determinante e decisivo ao passado do ator, e de modo mais particular a todas as primeiras experiências (no mais das vezes consideradas homogêneas) vividas na primeira infância (por exemplo, as diferentes teorias psicológicas e neuropsicológicas, a teoria psicanalítica e a teoria do habitus...) e, do outro lado, os modelos que descrevem e analisam momentos de uma ação sem se preocupar com o passado dos atores (teoria da escolha racional, individualismo metodológico, interacionismo simbólico, etnometodologia). No primeiro caso, as experiências passadas estão no princípio de todas as ações futuras. No segundo caso, os atores são seres desprovidos de passado, obrigados apenas pela lógica da situação presente: interação, sistema de ação, organização, mercado, etc. (Lahire, 2002:46).
\end{abstract}

Essas tendências opostas coexistem e comunicam algo pelo fato de os indivíduos realmente experimentarem uma socialização primária relevante, mas que não enrijece as ações ou não impossibilita mudanças ante uma experiência social secundária e diante das complexidades da ação presente. A proposta teórica que aqui se projeta, para estudar o envolvimento parental, é essa perspectiva de Lahire (2002:47), que assume ter a intenção de "tratar teoricamente a questão do passado incorporado, das experiências socializadoras, evitando negligenciar ou anular o papel do presente (da situação)”.

Propõe-se analisar a ação de escolha/tentativa de escolha da escola e acompanhamento escolar dos pais tanto a partir do seu passado disposicional, quanto pela realidade escolar que se coloca como o contexto de ação desses atores. Dessa forma, busca-se ultrapassar a relação já bastante explorada entre capitais socioeconômico e cultural e envolvimento parental, adicionando, aqui, a variável contexto escolar como um fator explicativo para o envolvimento parental, já que, como Lahire $(2002 ; 2004)$ mostra, os contextos e situações podem engatilhar ou desestimular determinados padrões de ação já incorporados ou abrir espaço para formações de novos esquemas de ação. No que tange ao envolvimento parental, determinados contextos escolares e sociais podem desencadear padrões de ações mais ou menos intensos de mobilização familiar tendo em vista o processo de escolarização e profissionalização dos filhos, sobretudo com relação aos conflitos distributivos atuais e à exigência do conhecimento para os circuitos produtivos contemporâneos.

A partir dessa proposta teórica de Lahire, é importante pensar, para qualquer empreendimento que busque interpretar as ações dos indivíduos, a relação entre o passado e o 
presente. Ao perceber a pluralidade de resultados, a despeito do passado incorporado, as fugas de tendência, Lahire $(1997 ; 2002)$ conclui que as disposições estão sempre sob condições ante o campo de possibilidades presentes. Determinados contextos podem provocar um desencadeamento de determinados esquemas de ação, inibir determinados padrões, ativar outros ou até mesmo dar as bases para os processos de socialização secundária e formação disposicional posterior, a depender da existência de determinados contextos desencadeadores. Ele considera de forma muito enfática que

\begin{abstract}
Mais do que supor a sistemática influência do passado sobre o presente ou, dito de outro modo, mais do que imaginar que todo o nosso passado, como um bloco ou uma síntese homogênea, influencia a cada momento sobre todas as nossas situações vividas (as abordagens estatísticas, probabilistas, nos ensinam que o passado de um ator abre - e fecha - seu campo de possibilidades presentes, mas em nenhum caso podem descrever a relação passado-presente em termos de causalidade, por exemplo), o campo de investigação proposto aqui levanta a questão das modalidades de desencadeamento dos esquemas de ação incorporados (produzidos no decorrer do conjunto das experiências passadas) pelos elementos ou pela configuração da situação presente, isto é, a questão das maneiras como uma parte - e somente uma parte - das experiências passadas incorporadas é mobilizada, convocada e despertada pela situação presente (Lahire, 2002:52).
\end{abstract}

Ele continua e afirma que "se a situação em si não explica nada, é ela que abre ou deixa fechados, desperta ou deixa em estado de vigília, mobiliza ou deixa como letra morta os hábitos incorporados pelos atores" (Lahire, 2002:53). Sem apelar para um microsituacionismo fenomenológico, Lahire insta por uma sociologia da ação que equacione, num mesmo fôlego teórico-metodológico, as estruturas incorporadas ao longo dos processos de vivências sociais dos indivíduos, sem, no entanto, desconsiderar a variabilidade contextual presente - contexto esse que é interpretado reflexivamente pelos indivíduos. Ele lembra que "é bastante surpreendente ver como a tradição sociológica, que põe o acento no 'peso do passado', pode, no final das contas, negligenciar o papel da situação presente que 'decide', não obstante, muitas vezes, o que do passado poderá ressurgir e agir na ação presente”. (Lahire, 2002:54).

Propõem-se aqui pensar em uma abordagem que foque nos contextos de ação e nas variações sincrônicas das disposições. Bernard Lahire chama atenção para a necessidade de uma abordagem disposicionalista que se volte também para o tempo presente da ação. Lahire (2015:1393) indica a necessidade de se "contextualizar o presente e o passado dos investigados". Ou seja, não somente focar nas trajetórias e no passado dos indivíduos, mas construir uma narrativa disposicionalista que considere o contexto de ação: 
Um disposicionalismo muito mecanicista poderia chegar até a pretender que tudo é constituído - ou ao menos em estado embrionário - desde a origem. [...] tudo se passa como se as disposições fossem constituídas independentemente de suas relações com o contexto de ação considerado (Lahire, 2015:1400).

Essa saída teórica de Lahire, que radicaliza a pluralidade disposicional e pluralidade de ação dos indivíduos, não pode ser compreendida sem levar em consideração todo um debate, já antigo, em torno da interpretação das ações dos indivíduos. Lahire é um sociólogo contemporâneo, que tem relevante produção recente, entre as décadas de 1990 e 2000 . Isso o coloca numa posição privilegiada no debate em torno da sociologia da ação e da educação. É por isso que sua obra é considerada como um prolongamento crítico da obra de Bourdieu ${ }^{1}$, que não só complexifica a teoria do habitus, mas busca responder a críticas feitas por outras perspectivas teóricas como a perspectiva do ator racional, a teoria dos jogos, entre outros. De igual maneira, a busca por um projeto de interpretação que equacione o passado incorporado e o presente da ação responde a questões colocadas pelo debate do individualismo metodológico, sobretudo em torno dos processos de socialização, que podem ser primários e secundários, como bem pontuaram Berger e Luckmann (2011).

A proposta de Lahire busca responder a esse incessante movimento de compreensão e decantamento das ações humanas, enquanto seres sociais, por parte da sociologia. Sem fazer uma ruptura entre o macro e o microssocial, essa abordagem busca esclarecer e melhorar o modelo de compreensão sociológica sobre como agem os indivíduos e o que, ao final, determina suas ações. Lahire pontua, já ao final de sua obra mais central, que:

\footnotetext{
Os atores atravessaram no passado e atravessam permanentemente muitos contextos sociais (universos, instituições, grupos, situações, ...); eles são os frutos (e os portadores) de todas as experiências (nem sempre compatíveis, nem sempre acumuláveis, e às vezes altamente contraditórias) que viveram em múltiplos contextos. [...] Dito de outro modo, o ator individual é o produto de múltiplas operações de dobramentos (ou de interiorização) e se caracteriza, portanto, pela multiplicidade e pela complexidade dos processos sociais, das dimensões sociais, das lógicas sociais, etc., que interiorizou. Essas dimensões, esses processos ou essas lógicas (essas contexturas) dobram-se sempre de maneira relativamente singular em cada ator individual, e o sociólogo, que se interessa pelos atores singulares, encontra em cada um deles o espaço social amassado, amarrotado. Se o ator individual é um ser dos mais complexos, é porque nele se encontram dimensões lógicas ou processos variados. Há tempo a sociologia tem o hábito de estudar essencialmente as estruturas planas (os processos sociais, os grupos sociais ou as estruturas sociais), isto é, o social em sua forma desdobrada e desindividualizada. Mas pouco a pouco, a sociologia interessou-se por essas múltiplas operações de dobraduras constitutivas de cada ator individual, essas amassaduras sempre particulares que fazem de cada ator, ao mesmo tempo, um ser relativamente singular e um ser relativamente análogo a muitos outros (Lahire, 2002:198).
}

\footnotetext{
${ }^{1}$ Cf. Tese de Cláudio Nogueira (2004).
} 
Esse projeto por uma sociologia disposicionalista, ou sociologia da ação completa, inclui pensar a não unicidade dos processos formativos e a não linearidade das respostas dos indivíduos, o que implica pensar numa formação disposicional plural, variada e no reconhecimento da capacidade de agência e reflexividades que os atores têm e manifestam ante as diversas situações de demanda e circunstâncias sociais.

\section{Reflexividade como uma das lógicas de ação}

Chama-se a atenção para a necessidade de se pensar a reflexividade presente nas ações e práticas dos indivíduos, em um contraponto específico a outras perspectivas reprodutivistas da estrutura social, mas sem desconsiderar os esquemas de processo socializador passado. Para isso, entre muitos outros esforços, ele (Lahire, 2002:145-151) evoca a metáfora do jogador. Apesar de o jogador profissional ter incorporado as disposições do esporte e os treinos, ele age reflexivamente no momento em que se decorre o jogo: faz paradas técnicas, analisa a melhor estratégia, conversa com o técnico, projeta ações, corrige movimentos, mesmo ante a velocidade e intensidade de uma situação de partida. Isso mostra um certo agenciamento do indivíduo sobre o próprio patrimônio de disposições em relação aos contextos e situações que se impõem. Ou seja, é possível perceber e explicar a ação do indivíduo alargando-se instrumentalmente o tempo da ação, focando no contexto da ação como um processo, onde se percebe a presença das disposições incorporadas e as estratégias e projetos manipulando essas disposições. Esse mesmo jogador, com suas habilidades desenvolvidas, pode ter um comportamento diferente em um jogo entre amigos e ficar muito mais atento e disposto a empreender singular esforço numa final de campeonato, por exemplo. Isso é uma ilustração de como os indivíduos se posicionam de forma plural em diferentes contextos de ação, em diferentes intensidades e objetivos. As variações sincrônicas da realidade também impactam na formação disposicional e, por fim, na ação, quando no tempo presente. Dessa forma, Lahire (2002) evidencia que os contextos de ação impõem diferentes intensidades, criticidades, familiaridades, possibilidades e interdições aos atores.

Certamente, tudo depende da maneira como se divide a ação considerada, mas certas ações são organizadas num tempo claramente mais longo que aquelas que nos são dadas a ver nos exemplos de gestos esportivos [...] Se, no momento em que o jogador está no jogo, pode contar apenas com suas habilidades incorporadas, estas podem ser o produto de todo um trabalho de reflexão, correção, de cálculo, de estratégia, etc., acumulado durante horas de treino (Lahire, 2002:148-149). 
Além disso, a própria formação disposicional do ator não é de todo pré-reflexivo. Ainda dentro da metáfora do jogador, todo o treino e modelamento corporal é fruto de um desejo refletidamente buscado. Essas metáforas de jogos, amplamente utilizadas, não obstante, focam num tipo particular de ação, emergencial, sempre em prontidão, em monitoramento. A vida real, no entanto, é mais diversificada e as lógicas de ação são inúmeras, gradativas e imiscuídas.

Certamente, a pessoa não pode conduzir toda a sua vida dentro do cálculo racional ou da intenção, mas numa vida nunca inteiramente controlável, previsível, planificável, etc., os atores podem às vezes desenvolver intenções, planos, projetos, estratégias, cálculos mais ou menos racionais, em tal ou tal domínio, por ocasião desta ou daquela prática. Portanto, as observações críticas sobre a intencionalidade e o cálculo consciente valem para um tipo particular de ação, numa escala particular de construção de contextos de ação, mas não de maneira universal (Lahire, 2002:154).

Aquino (2000) chama atenção para o fato de que a teoria do ator racional e a teoria do habitus não são necessariamente antagônicas, mas são antes complementares, por narrarem sobre níveis de ação diferentes. Ele considera que

É de se esperar que as sociedades modernas, caracterizadas pelas mudanças rápidas, coloquem os indivíduos diante de um maior número de situações novas, difíceis de associar a situações passadas a partir dos seus esquemas de percepção e para as quais, por conseguinte, não encontram esquemas de ação adequados. Em tais situações, os sujeitos são obrigados a agir reflexivamente. É na investigação de situações encontradas em sociedades tradicionais que melhor se percebe o agir humano enquanto ação prática. Nas sociedades capitalistas modernas, além de ser maior o número de situações novas, o uso generalizado do dinheiro oferece um maior número de oportunidades para se observar os atores agindo racionalmente (com relação a fins, inclusive) (Aquino, 2000:28).

Para Lahire, no entanto, é preciso, numa mesma teoria da ação, buscar dar conta ou considerar seriamente essas diversas lógicas de ação e níveis de reflexividade. Ele considera que

[...] é de capital importância apreender da melhor forma possível a parte reflexiva, calculadora, planificadora da ação (momentos em que a ação é preparada, calculada, planejada, mas também é refletida imediata ou posteriormente) e a parte da ação préreflexiva, não planejada, não calculada, segundo os tipos de ação e as categorias de atores considerados. Em vez de postular a priori e de uma vez por todas a existência de uma teoria da decisão, teoria do jogo, teoria do senso prático, teoria da ação situada...), é preferível reconstituir, segundo os universos sociais e os meios sociais, segundo os tipos de atores e os tipos de ação, os diferentes tempos da ação e as diferentes lógicas de ação - tempos da discussão, da deliberação [...], da preparação, do planejamento, tempo de pôr em prática esquemas de ação incorporados na urgência relativa acompanhados, às vezes, de tempos de pausa, de reflexão e de correção, tempos de volta à ação, a si, etc. Em resumo, trata-se de desenvolver uma sociologia da pluralidade das lógicas efetivas de ação e da pluralidade das formas de relação à ação (Lahire, 2002:157-158 [Grifo nosso]). 
Lahire (2006) destaca as variações sincrônicas e diacrônicas da formação do patrimônio individual de disposições, ou seja, sobre a variabilidade do processo socializador e sobre a coexistência de esquemas heterogêneos. De igual modo, ele (Lahire, 2006; 2015) destaca a variabilidade contextual da ação. Essa noção de variação contextual da ação implica pensar que o ator percebe, reconhece, interpreta e mobiliza ou inibe determinadas competências e disposições. Lahire (2002:59) lembra que:

[...] as situações sociais (das formas mais formais e institucionais às mais informais) nas quais vivemos constituem verdadeiros 'ativadores' de resumos de experiências incorporados que são nossos esquemas de ação (no sentido amplo do termo) ou nossos hábitos e que dependemos assim fortemente desses contextos sociais (institucionais ou não institucionais) que "tiram" de nós certas experiências e deixam outras em estado de gestação ou de vigília.

No âmbito do envolvimento parental, é possível supor que determinados contextos escolares e sociais podem mobilizar ou inibir determinadas atitudes dos pais em relação à vida escolar dos filhos. Mesmo pais com baixa escolaridade, com pouca presença dos seus próprios pais em suas trajetórias de vida, mesmo pais com baixa renda, podem passar a mobilizar ações em prol da vida estudantil e profissional de seus filhos, tendo em vista fatores contextuais, existência de oportunidades, debates e valores públicos e situações externas outras que podem ativar disposições ou até mesmo criar competências.

\section{Sobre a metodologia e contextos}

Tendo em vista os objetivos do artigo, são aqui analisados quatro casos de pais, oriundos de uma pesquisa maior, realizada entre 2015 e 2016, no Ceará. Essa pesquisa ${ }^{2}$ tinha por objetivo analisar a configuração social presente nas Escolas Estaduais de Educação Profissional, bem como motivações e estratégias mobilizadas, o que incluiu analisar os dados do Questionário Socioeconômico do ENEM, edições 2012, 2013 e 2014, seguido de uma pesquisa em campo com duas dessas escolas em Fortaleza, por meio de questionários com alunos e entrevistas com os seus pais. Foram 653 questionários no total, e sorteadas dez famílias para entrevistas.

As entrevistas foram feitas com os pais dos alunos que participaram do questionário, o que permitiu um contato inicial. Algumas foram feitas com ambos os pais e outras com

\footnotetext{
2 Cf. Vários detalhes, informações e dados citados nesse artigo estão minuciosamente apresentados na dissertação da pesquisa em questão (Santos, 2017), o que não poderia ser feito aqui ante a limitação de espaço e os objetivos.
} 
apenas o pai ou mãe. Aconteciam em geral no domicílio da família ou na escola, em espaço reservado. Ressalta-se que foram várias as composições familiares encontradas ${ }^{3}$ e o uso do sorteio a partir de uma análise de agrupamento permitiu diversidade socioeconômica.

É importante contextualizar que essas escolas (EEEP) são oriundas de uma política de educação profissional do Ceará, iniciada em 2008. São escolas com infraestrutura diferenciada, orçamento diferenciado, com seleção tanto para alunos como para professores. Na ocasião, eram 112 dessas escolas presentes no Ceará, representando um pouco mais de dez por cento da oferta de ensino médio. São escolas que apresentam nítido melhor desempenho nas avaliações externas e estão entre as que mais tem egressos no ensino superior entre as escolas públicas estaduais. Atualmente, há ainda outras modalidades de escolas que complexificam ainda mais o quadro de oportunidades do nível médio público cearense.

Aqui, o objetivo é reelaborar teoricamente a análise desses casos, dentro dessa abordagem disposicionalista-contextual a partir de Lahire. O uso de apenas quatro dessas entrevistas se faz pela necessidade de síntese e pela opção por um aprofundamento teórico e de análise específica desses casos, o que diminui a necessidade por quantidade. Dessa forma, pode ser visto, então, como um ensaio para pesquisas futuras sobre envolvimento parental, em maior escala, que estejam comprometidas com tal perspectiva sociológica de interpretação da ação.

\section{Escolha e acompanhamento escolar como uma situação social e a análise dos casos}

Os processos de escolha e acompanhamento escolar são impactados pelas condições contextuais de oferta educacional e oportunidades do sistema. A existência dessas escolas de tempo integral articulada à educação profissional não se constitui apenas por essas características, mas em relação a todo contexto escolar anterior e presente.

Essas escolas surgem dentro de um sistema bastante homogêneo em termos de tipos de oportunidades de nível médio. Além de escolas públicas mais tradicionais e históricas, presentes em todo o território nacional, havia somente, no Ceará, os Liceus, que são escolas com alguma diferenciação em termos de infraestrutura e política pedagógica. As EEEPs surgem como uma opção de formação em tempo integral, articulada à alguma profisssão, com

\footnotetext{
${ }^{3}$ A partir de pontuações feitas por Clarissa Neves (2013), elabora-se, para os fins metodológicos desta pesquisa, o seguinte conceito de família, em dois níveis: Família nuclear se caracteriza pela existência de um ou mais filhos em relação de dependência afetiva e material com um ou mais adultos, vivendo todos ou partes destes em um espaço doméstico compartilhado. Família ampliada é a rede mais ampla de parentesco, de qualquer tipo ou grau, em que está situada a família nuclear. $\mathrm{O}$ foco da pesquisa foi sobre a família nuclear.
} 
maior capacidade de inserção dos seus egressos no ensino superior e no mercado de trabalho, como estágio remunerado obrigatório no terceiro ano e, sobretudo, escolas com disciplina diferenciada e sendo escolas totalmente gratuitas. Por ser um projeto novo, agenciado pelo estado, foi acompanhado de perto, com investimentos especiais. Todo esse cenário repercutiu entre os pais e alunos, sobretudo nos anos finais do ensino fundamental, que viram nesse modelo de escola uma oportunidade de melhor formação a baixo custo.

Há um processo de seleção para matrículas nessas escolas, feito por meio do boletim do nono ano, considerando a média das notas dos alunos candidatos. Obviamente essa seleção cria uma restrição, o que faz com que um grupo também diferenciado de alunos entrem, porém, não tanto, sendo alunos de famílias com renda baixa ou média-baixa, como mostram os dados do questionário socioeconômico do ENEM, o que não destoa muito do encontrado nas demais escolas estaduais públicas regulares ${ }^{4}$. Essas escolas, por tais características e pelo quadro de oportunidades escolar público restrito, acabaram por atrair alunos e pais de escolas privadas. Por meio de uma mobilização judicial por parte de uma associação de pais, foram garantidas até $20 \%$ das vagas para alunos oriundos da rede particular (Castro, 2013). Essas eram famílias que sobretudo mantinham seus filhos em escolas particulares não centrais, como considerado por Nogueira (2013), e que viram na EEEP uma saída gratuita e melhor de escolarização de nível médio para seus filhos.

Esse é o contexto, com suas limitações e potencialidades, com o qual as famílias interagem. É partir desse contexto que se constituem os contextos de ação, na relação com as condições sociais e culturais desses pais. A partir disso, é possível avançar na análise do processo de envolvimento parental, ou seja, do processo de escolha da escola e acompanhamento da vida escolar dos alunos.

Ensaia-se a ideia de situação social como toda situação onde há uma demanda e necessidade por ação ou escolha. Ou seja, é a situação que se constitui no momento em que um indivíduo é demandado a agir ou escolher algo, essa ação ou escolha, não obstante, possui uma margem de possibilidades que é limitada ou potencializada tanto por externalidades contextuais quanto pelas internalidades do sujeito, seu passado incorporado. Dessa forma, pode-se compreender e interpretar as ações dos indivíduos. É partir das considerações teóricas e metodológicas de Bernard Lahire que se mobiliza aqui essa noção. Quando ele diz que é necessário observar "os mesmos atores em mais de duas cenas ou além de dois tipos de situação social" (LAHIRE, 2002:202), está dizendo, ao cabo, que não só o patrimônio de

\footnotetext{
${ }^{4}$ Cf. Santos (2017).
} 
disposições, o passado incorporado ou o habitus determinam as ações dos indivíduos, mas que tal interpretação se dá entre a articulação do passado incorporado e o presente da ação. Sobre uma possível infinidade de possibilidades de ação, ou de uma singularização exagerada, Lahire, em entrevista recente comenta:

\begin{abstract}
O que vemos constantemente são indivíduos que tomam decisões ou fazem escolhas na interseção de restrições externas (contextuais) e internas (disposicionais). Até o modo de tomar uma decisão é diferenciado socialmente. Alguns atores individuais adquiriram, graças à escola em particular, ferramentas de reflexividade, hábitos de deliberação, cálculo, equilíbrio dos elementos positivos e negativos, etc. Mas esse tipo de equipamento mental está desigualmente distribuído na população (Lahire, 2016 [Tradução nossa]).
\end{abstract}

A situação social possui uma dimensão temporal e espacial e pode ser composta por ou compor - outras situações sociais, mas sempre limitada em termos de resultados por causa das restrições socialmente determinadas, sejam restrições contextuais do tempo presente da ação, sejam restrições incorporadas ao longo dos processos de socialização vivenciados pelos indivíduos. A situação social serve como ferramenta analítica para se pensar como uma determinada escolha/ação pode ser resultado tanto dos (I) contextos, em suas interdições e possibilidades, quanto (II) dos patrimônios individuais de disposições. Assim, ao se adicionarem contexto, passado e processo ao ato de agir/escolher, tem-se uma situação social. É importante alargar a narrativa sobre o processo em que se deu a ação, na interlocução com os sujeitos da pesquisa, e assim perceber possíveis variações, possibilidades consideradas ao longo da situação de demanda pela ação/escolha, o que ajuda a entender os esquemas de ação desses indivíduos e como interagiram com o contexto ${ }^{5}$.

\title{
Família 1
}

José Jerônimo e Clara $^{6}$ são os pais dessa família de renda baixa, que moram na periferia de um bairro de classe média de Fortaleza. A renda deles oscila entre um e um salário mínimo e meio, oriunda do trabalho de porteiro que José desempenha por décadas. Clara cuida das atividades domésticas. Ambos não terminaram o ensino fundamental, nasceram e cresceram na própria capital, descendem de populações praianas e enfrentaram as adversidades da pobreza numa metrópole.

\footnotetext{
${ }^{5}$ Weber e Luhmann inspiram a pensar não apenas sobre o que foi, mas sobre o que poderia ter sido, e se poderia, porque poderia e porque não foi.

6 Todos os nomes apresentados são fictícios.
} 
Possuem dois filhos, o mais velho, na ocasião com 16 anos, no primeiro ano do ensino médio e uma filha de nove anos, no quarto ano do fundamental. O filho, João Marcos, estuda em um Escola Estadual de Educação Profissional do bairro em que eles moram, essa, no entanto, não era a escola que ele queria. João queria uma escola de turno simples, para poder, no contraturno, trabalhar e assim "comprar as coisinhas de jovem". Seu pai discordou e insistiu para que ele fosse para uma EEEP, não apenas verbalizou, mas se comprometeu a fazer "bicos" e "tirar folgas" de outros porteiros para poder "fazer algum dinheiro" para que João, entre outras coisas, pudesse comprar um notebook. E assim aconteceu.

O processo de escolha da escola de ensino médio começa em meados do nono ano, quando o pai, apesar da extensa carga horária de trabalho, ia a escola para saber mais sobre as opções de ensino médio. A escola de ensino fundamental indicou que ele procurasse saber sobre as EEEPs, pois o João "tinha bom desempenho e podia tentar a seleção". O pai procurou mais informações e viu que uma escola de tempo integral e com formação técnica podia oferecer ao João "uma educação que ele (José) não teve". João quer entrar na universidade, o que é apoiado pelos pais. Quer cursar administração, seguindo na mesma área do curso técnico que atualmente faz na EEEP. José acredita que os jovens devem estudar primeiro, terminar a faculdade, e depois procurar trabalho, da mesma forma como acontece com "os meninos do prédio" em que ele trabalha. A mãe enfatiza que dispensa João de todas as atividades domésticas, para ele se dedicar exclusivamente aos estudos, isso "porque o estudo integral é melhor, mas é puxado”.

Esse caso mostra uma considerável mobilização, sobretudo do pai, pela busca de uma melhor oportunidade escolar para o filho. A existência desse modelo de escola, com o turno integral, é o primeiro elemento contextual. O pai considera que mais tempo na escola é melhor e busca garantir que seu filho aproveite essa oportunidade. No entanto, isso também está atrelado à disposição da escola de ensino fundamental de indicar e incentivar a EEEP, uma vez que muitas famílias a desconhecem. Além disso, o histórico do aluno e a crença de que ele poderia "se dar bem" é compartilhada pela escola anterior e pelos pais, que arriscam o esforço.

O que se tem diante desse caso é uma série de situações sociais de maior oportunidade, flexibilidade e incentivos externos que juntos constituem o contexto de ação em que a família opera sua escolha e esforço. Sem a EEEP, não haveria razão de turnos extras por parte do pai, o filho provavelmente estaria numa escola regular e trabalhando num emprego de baixa remuneração, o que muito provavelmente afetaria seu rendimento e diminuiria as chances de entrada no ensino superior. Se a escola de ensino fundamental não operasse incentivando, 
talvez o mesmo teria ocorrido. Se João não "fosse um menino caseiro" e "estudioso" talvez não merecesse o esforço dos seus pais. Ou mesmo se José não fosse um homem observador, e, talvez por isso, bom porteiro, e desejasse aos seus filhos uma trajetória semelhante à dos jovens do prédio onde trabalha.

O objetivo aqui é ressaltar essas séries de situações e elementos contextuais que, junto a características individuais dos pais, seus conjuntos de crenças e modos de agir, possibilitam uma atitude de investimento escolar que superam ou que vai na contramão dos seus capitais econômicos e culturais, que são muito baixos.

\section{Família 2}

Tainá é aluna do terceiro ano de uma EEEP, onde cursa o técnico de enfermagem. Seu objetivo é entrar numa universidade pública e cursar medicina. No ano anterior, já havia feito a prova do ENEM para praticar e obteve bom desempenho. Seus pais são divorciados e foi o seu pai, Flávio, quem participou da entrevista.

Flávio trabalha numa empresa de médio porte em Fortaleza, na área de Recursos Humanos (RH) e, na ocasião da entrevista, estava terminando curso superior em Gestão de RH, apesar de já ter feito curso na área de Tecnologia da Informação, porém incompleto. Foram quatro filhos no primeiro casamento e três no segundo. Sete filhos no total, que demandam tempo e dinheiro. Todos estudam em escolas púbicas, porque não haveria recursos para manter todos os filhos em escolas particulares, apesar, de como ele disse, investir tudo que pode em cada um: "cada um tem seu notebook e internet, comida e roupa de qualidade". Ele se considera bem "dinâmico". Durante a entrevista usou várias metáforas do trabalho no $\mathrm{RH}$ e falava livremente, com bastante desenvoltura.

A filha mostrou-se protagonista sobre a escolha da escola de ensino médio: "com a Tainá não tem decisão... não tem discussão... ela já chegou e disse - 'eu quero ser médica, vou para a EEEP, tem curso de enfermagem lá, a escola vai me dar uma boa base' - e tchau e benção". Perguntado sobre o turno integral: "super tranquilo... até porque Tainá é muito determinada... ela tem muita força de vontade, sabe!?”. Houve, no entanto, um problema para participar da seleção. A escola negou a participação da aluna no processo de seleção pela sua idade, que na ocasião, era abaixo do permitido pelas diretrizes da SEDUC. A diferença de idade, no entanto, "era de apenas alguns meses". A filha acionou o pai, que foi à escola inúmeras vezes, bem disposto a garantir a participação da filha. Não conseguindo resolver via escola, foi à sede da SEDUC para falar com alguém que pudesse resolver a questão, também 
não obteve sucesso. A saída encontrada por ele foi "ficar plantando na recepção da SEDUC" e esperar passar a secretária de educação, sobre a qual pesquisou extensivamente, inclusive sobre exceções anteriores já feitas. Abordou a secretária estadual, foi incisivo, enfático e "até chato", e por meio do ele chamou de "telefonema santo", conseguiu garantir a participação da filha na seleção. Ela passou e garantiu a matrícula.

Flávio reconheceu que "poderia ter feito mais pelos filhos", sobretudo aos do primeiro casamento. Ele diz que busca compensar o afastamento inicial que teve e a aproximação atual que tem com os filhos hoje é uma forma de "pagar" pelos seus erros do passado. Por isso, ele faz questão hoje de visitar todas as escolas dos filhos, de "dá umas incertas lá", aparecendo mesmo não sendo chamado. Busca ir ao cinema, teatro e praia com eles, revezando os filhos por finais de semana.

Quando surgem barreiras burocráticas impostas pela escola, ou seja, uma situação de crise menor dentro dessa situação de escolha escolar que vinha se processando, o pai opera reflexivamente e estrategicamente, traçando iniciativas junto à escola e à SEDUC. Se a escola não tivesse feito importância sobre a pequena diferença de idade da aluna, essa situação de matrícula seria menor temporalmente e menos crítica, demandando menos esforço. Vale ressaltar, no entanto, que se a mesma situação tivesse acontecido com a Família 01, ou seja, uma situação de maior inflexibilidade no processo de matrícula, é possível que José Jerônimo não conseguisse empreender ações desse tipo junto à escola e à SEDUC, ou enfrentar o discurso pedagógico e burocrático, em vista de seu baixo capital cultural.

Outro ponto tem relação com a espécie de "dívida" paternal que Flávio tem para com os filhos do primeiro casamento, o que pode explicar, contextualmente, o seu empenho no processo escolar da filha. Além disso, ele reconhece o comprometimento e bom desempenho dela. Dessa forma, percebe-se uma interação entre disposições socioeconômicas e culturais, contextos e interdições, o que implica perceber que nem o envolvimento parental, nem o sucesso escolar são processos lineares, dependentes dos capitais econômicos e culturais ou processos totalmente independentes destes.

\section{Família 3}

Franciene, mãe, empregada doméstica, ensino médio incompleto. Ela e a filha são de Teresina-PI e foram morar em Fortaleza, por influência do então marido, quando Luane tinha apenas três anos. Franciene tinha vontade de fazer um curso técnico quando jovem, mas a gravidez precoce, entre outros fatores, dificultou esse objetivo, o que também a impediu de 
concluir o ensino médio. Ela conta também sobre como teve dificuldades de conciliar o seu trabalho com os cuidados da filha quando pequena. $\mathrm{O}$ pai foi sempre ausente, mais ainda depois da separação. Ela soube da EEEP por meio de amigos e por anúncios televisivos, além disso, tinha um sobrinho que estudava numa escola integral no Piauí, o que ela tinha por bom exemplo e a fez procurar por algo congênere no Ceará.

Luane, filha única, fez todo o fundamental em escolas particulares do seu bairro, escolas que ela e a mãe criticam pela desorganização e "falta de disciplina", sendo a EEEP "muito, muito mais organizada". Luane queria o curso técnico de enfermagem, mas não conseguiu a classificação necessária e ficou no técnico de comércio. Tem o desejo de trabalhar após o término do ensino médio e pretende cursar superior em Psicologia paralelamente. Espera ansiosa pelo estágio obrigatório e remunerado, via escola, no terceiro ano. A mãe lembra que ela nunca reprovou de ano e sempre teve bom desempenho na escola, além de ser uma "menina calma".

Essa família traz um fato interessante sobre como se (re)constituem as expectativas a partir de uma formação diferenciada. Se Luane não tivesse conseguido entrar na EEEP, elas se mudariam de volta para o Piauí: “antes dela passar na seleção... nós já tava de mala pronta para voltar pro Piauí". Franciene lembrou que não tinha nenhum parente em Fortaleza e que só ficou porque a filha "passou na profissionalizante". E continuou: "se ela conseguir emprego aqui, ou passar na faculdade... e acho que vai... eu fico também". Ela tem expectativa de que a formação em tempo integral "prepara melhor o jovem", que "força mais", e que a formação técnica é uma chave para a empregabilidade, curso técnico esse que Franciene não conseguiu fazer em sua juventude. Mesmo que a formação da EEEP não reflita necessariamente em maior empregabilidade, a crença nesse modelo é clara, o que as fizeram mudar de planos, inclusive. A mãe lembrou que quer um "futuro" para a filha que ela "não teve", que tenha "independência", e Franciene acredita que a EEEP vai ajudar a filha nesse sentido, mesmo sendo o tempo integral "cansativo".

A existência de uma oportunidade escolar diferenciada e gratuita é um contexto externo que interage com as condições sociais dessa família, eque, aliado a um desejo particular por escolarização e profissionalização, gera uma situação social que demanda ajuste das ações. 


\section{Família 4}

Samara mostra-se independente e buscou ela própria a EEEP. Conheceu essa escola por meio de colegas de escolas passadas que agora estudavam numa EEEP. Ela está cursando o técnico em enfermagem e deseja fazer medicina. Afirma gostar do modelo da escola e acha que isso a ajudará na vida profissional e a entrar no ensino superior. Ressalta-se que a aluna protagonizou a escolha da escola, os pais foram apenas para "assinar" e raramente vão à escola.

Marcos, o pai de Samara, que participou da entrevista, tem formação superior em Turismo, trabalhou no Consulado Brasileiro de Sucre na Bolívia e acumula várias outras experiências profissionais importantes. Tem vários parentes bolivianos e vários irmãos médicos, e ele mesmo chegou a cursar medicina no passado. Sua ex-esposa, Cristina, é da Argentina e é jornalista. Ele diz gostar da escola em geral, mas não imprimiu muitas positividades por ser de turno integral, por ter curso profissionalizante ou por ter estágio remunerado. Ele gostou da opção da filha pelo fato da escola ser "perto da casa da mãe deles" e por possibilitar o acesso ao sistema de cotas. Para essa família e muitas outras: "é melhor uma boa escola pública com acesso às cotas do que uma escola particular mediana sem acesso ao sistema de cotas".

São quatro os filhos, todos estudavam em "boas escolas" particulares de Fortaleza, mas tiveram reveses financeiros que, junto à separação do casal, fizeram com que os filhos, na ocasião do nível médio, tivessem que ir para a escola pública ou ter bolsas de estudo em escolas confessionais.

Marcos reconhece que poderia ter investido mais na relação e na escolarização dos filhos mais velhos, mas acha que o filho mais novo, deficiente auditivo e que tem outras complicações, merece mais atenção e cuidado. Ele inclusive percebe nos outros filhos uma certa "angústia" pelos pais terem dado muita atenção ao filho mais novo. Marcos deixa transparecer que a vinda para o Brasil e o nascimento do filho mais novo causaram muita mudança. Uma delas foi o abandono da carreira na área do Turismo para se dedicar ao artesanato.

Perguntado sobre quem é o maior responsável pelo sucesso escolar do aluno, a resposta foi: "o aluno... se ele quer... ele tem sucesso... se ele não quer... não tem professor não tem escola não tem pai não tem mãe não tem tio não tem parente nenhum que vai fazer ele mudar de ideia... a base fundamental do sucesso é você mesmo...”. Logo em seguida disse: 
“a não ser que seja algo do caso do Rogério, meu filho mais novo". Dias antes da entrevista, houve reunião de pais na escola da Samara, nem Marcos, nem Cristina foram.

Os dois filhos mais velhos estão "encaminhados na vida", eles estavam terminando o ensino superior na ocasião, mas passaram a morar sozinhos mesmo antes de entrar na universidade. Samara, na ocasião da pesquisa, estava no terceiro ano na EEEP e queria se mudar para a Bolívia para morar com os tios e seguir carreira médica. $\mathrm{O}$ filho mais novo vive com a mãe.

A situação que se tem nessa família é a de um forte envolvimento parental pelo filho mais novo, que de fato necessita de mais cuidados. Isso forçou os demais filhos a encarar a vida estudantil de forma mais individual, sem contar com o apoio mais intenso dos pais.

Ambos os pais, com bom capital cultural e com certo capital econômico, conseguiram, também pelo contexto familiar favorável, transmitir isso aos filhos. No entanto, tem-se um processo de envolvimento parcial com a vida estudantil dos filhos mais velhos, reconhecido pelo próprio Marcos. No caso específico da EEEP onde Samara estuda, os seus pais não participaram diretamente da escolha dessa escola e apenas acataram a decisão da filha, diferentemente do que se viu com os demais pais da Famílias 1, 2 e 3.

O fato de o filho mais novo nascer com problemas de saúde e deficiência auditiva, as mudanças de país, entre outros fatores, são aspectos a se considerar na análise desse caso, que num primeiro olhar, seria de baixo envolvimento parental. Apesar do capital cultural desses pais, tem-se uma modalização do esforço por um dos filhos, e algo menos intenso para os demais. Esse caso mostra a necessidade de uma análise situacional da forma como operam as disposições incorporadas junto aos contextos e situações do presente, implicando o reconhecimento de que mais capital cultural ou econômico não equivale severamente a mais envolvimento parental. Em todas as circunstâncias, os diferentes contextos de ação modulam essa relação.

Um outro elemento contextual são as regras de acesso às cotas, que entram como um dos motivos para entrar na escola pública, sobretudo uma escola diferenciada como a EEEP. Um conjunto de situações, inclusive para além do próprio modelo escolar, estão imbricadas nesse processo de escolha escolar e envolvimento parental, onde operam várias lógicas de ação, como as estratégicas de longo prazo. 


\section{Avançando no debate}

Quando Katherin Barg $(2013$; 2015) muito bem apresenta a influência do capital cultural sobre o processo de escolha escolar na França e a relação desse capital com os processos de envolvimento parental, ela o faz no reconhecimento de um contexto francês específico, onde a escola de um nível de ensino recomenda ou não o(a) aluno(a) à escola de nível posterior. O capital cultural opera na capacidade dos pais de influenciar e articular com os professores, e nesse contexto, com mais mediação e restrições, o capital cultural é fundamental, como foi para o caso da Família 2.

Annette Lareau $(2007$; 2011) mostra a grande diferença na forma de se conduzir a educação e vida dos filhos entre famílias de classe média e de classes populares. As famílias de classe média criam seus filhos numa espécie de cultivo orquestrado e numa relação mais dialogal. Em contrapartida, os filhos das classes populares têm um cultivo mais natural, menos elaborado e numa relação mais hierárquica. A própria Lareau (2016), no entanto, reconhece que apenas o capital cultural e econômico dos pais não é o determinante, ou suficiente no que tange o envolvimento parental, ou a escolha da escola. Ela aponta que há uma série de questões do jogo escolar e arranjos institucionais que precisam ser contextualizadas e que tornam incerta a transmissão das vantagens sociais.

A pesquisa de Lahire (1997) explorou muito bem esses elementos disposicionais e contextuais que flexibilizam a nossa compreensão do processo de reprodução das desigualdades sociais pelo capital cultural institucionalizado, por meio do qual explica os casos de sucesso escolar mesmo em meios populares e em situações de desvantagens, mas sem abandonar o paradigma da socialização ou negando a existência de estruturas sociais.

A compreensão proposta neste artigo é de se pensar o envolvimento parental como um processo que não depende exclusivamente dos capitais sociais, econômicos e cultural dos pais, nem apenas dos seus esquemas disposicionais incorporados no passado, mas também de variáveis contextuais do presente. Esses contextos variam, sobretudo, em relação aos níveis de oportunidades escolares existentes, ao grau de liberdade e flexibilidade do processo de matrícula, aos estímulos externos pela permanência escolar e em relação à clareza e transparência dos processos. Todas essas externalidades tem implicações na forma como os indivíduos - no caso específico, os pais - vão agir. A partir da compreensão de Lahire (2002) e dos dados empíricos aqui e em outros lugares apresentados, tem-se que a constatação de que essas externalidades, ou contextos de ação, na relação complexa com o passado incorporado 
dos indivíduos é que constituem as situações sociais diversas, mobilizando lógicas de ações múltiplas.

Essas situações sociais e as demandas por elas provocadas podem se apresentar ao indivíduo de forma mais ou menos crítica, mais ou menos familiar, com mais ou menos disponibilidade de informação. Além disso, pode haver variações temporais, em que uma situação social ou uma demanda acaba por requerer mais esforço e tempo, e outras menos. Situações mais ou menos flexíveis e por fim, situações com mais ou menos oportunidades.

\section{Considerações finais}

A partir dessa proposta, situações onde se demandam ações dos sujeitos seriam o momento de interação entre o patrimônio individual de disposições e os contextos. Esses contextos são apresentados a partir das possibilidades permitidas pelo patrimônio disposicional, mas também por fatores alheios aos sujeitos (e.g. local, época, flexibilidade dos arranjos institucionais, organização política, entre outros) no tempo presente. Dessa forma, então, tem-se as margens contextuais. Esses contextos apresentam-se de forma mais ou menos diversificada, mais ou menos crítica, mais ou menos informada aos sujeitos, e eles podem interagir e agir de forma plural a partir dessas múltiplas formas de constituição dos contextos. Têm-se, portanto, margens de ação possíveis oriundas da diversidade disposicional, que incide, junto a fatores externos, na forma como os contextos vão se apresentar ao sujeito, quando a este forem demandadas ações. A forma ou modo como o contexto se apresenta é resultado direto e articulado do patrimônio disposicional com a conjuntura social alheia ao sujeito.

Quando se tem por objetivo explicar a ação dos indivíduos, assim como explicar porque tais escolheram $\mathrm{A}$ e não $\mathrm{B}$, tem que se empreender dois passos empíricos. O primeiro passo é analisar os patrimônios individuais de disposições. Com esse passo, é possível mapear como os indivíduos estão posicionados em termos de distribuição dos bens materiais e simbólicos e conjecturar sobre como estão situados na sociedade, o que determina as possibilidades contextuais em que o sujeito está ou estará em inserido. O segundo passo é analisar como os fatores externos se apresentam ao sujeito, levando em consideração que a forma como ele percebe e interage com tais fatores é fruto tanto da existência de tais exterioridades quanto das suas disposições. O passado disposicional mais os fatores externos determinam as margens contextuais do presente que por sua vez determinam as margens de ação futura. 
Quanto mais diversificado e possibilista for o patrimônio disposicional, mais possibilidades contextuais, e, quanto maiores forem as possibilidades contextuais e mais diversos os quadros externos, maiores serão as possibilidades de ação; é possível também que menos determinante sejam as estruturas do passado sobre a trajetória presente dos indivíduos, no caso específico, na trajetória escolar.

A principal crítica que Margareth Archer (1983) faz a Bourdieu e a Bernstein sobre o processo da reprodução das desigualdades está no fato de que os mesmos não contextualizaram os seus resultados para além do ensino francês, que à época era mais centralizado e mais linear que a de outros países. Além disso, ela considera (Archer 2007) que nas sociedades contemporâneas se tem um nível de diferenciação social e diversidade que implicam uma certa universalização de alguns capitais e conteúdos, típica dessas sociedades mais cosmopolitas. Agnès Zanten (2007) mostra que mesmo pais franceses de capital cultual não tão elevado conseguem operar minimamente com conceitos sociológicos, de alguma forma difundidos publicamente, e que isso impacta na escolha da escola e na forma como os pais concebem seu envolvimento na vida escolar dos filhos.

Diante disso, um investimento de pesquisa que esteja situado no debate disposicionalista, o que é bem presente na sociologia da educação pelo seu apreço aos processos socializadores, precisaria enfrentar essa tensão entre o passado incorporado e o presente da ação. É necessário elaborar teoricamente essa complexificação e diferenciação social/contextual que está em marcha. E, também, é necessário se desafiar a pensar uma sociologia da ação que explique as ações e as práticas dos indivíduos, tendo em vista os principais desenvolvimentos teóricos do campo, bem como os e seus prolongamentos críticos.

\section{Referências}

AQUINO, Jakson Alves de (2000), "As teorias da ação social de Coleman e de Bourdieu". Humanidades e Ciências Sociais, v. 2, n. 2, pp. 17-29.

ARCHER, Margaret Scotford (1983), "Process without system". European Journal of Sociology, v. 24, n. 1, pp. 196-221 [Consult. 21-03-2020]. Disponível em http://www.jstor.org/stable/23999220

ARCHER, Margaret Scotford (2007), Making our Way through the World: Human Reflexivity and Social Mobility. Cambridge, Cambridge University Press.

BARG, Katherin (2013), “The Influence of Students' Social Background and Parental Involvement on Teachers' School Track Choices: Reasons and Consequences”. European Sociological Review, v. 29 , n. 3, pp. 565-579. 
BARG, Katherin (2015), "Educational choice and cultural capital: examining social stratification within an Institutionalized dialogue between family and school". Sociology, v. 49, n. 6, pp. 11131132.

BERGER, Peter; LUCKMANN, Thomas (2011), A construção social da realidade: tratado de sociologia do conhecimento. Petrópolis, Vozes.

BOURDIEU, Pierre (2002), Esboço de uma teoria da prática, precedido de três estudos de etnologia Cabila. Oeiras, Celta Editora.

BOURDIEU, Pierre; PASSERON, Jean-Claude (2012), A reprodução: elementos para uma teoria do sistema de ensino. Petrópolis, Vozes.

CASTRO, Bruno (2013), Escolas profissionalizantes têm cota para alunos da rede privada. O Povo, Fortaleza, 29 nov. 2013 [Consult. 19-04-2018]. Disponível em: https://www20.opovo.com.br/app/opovo/cotidiano/2013/11/29/noticiasjornalcotidiano,3169955/esc olas-profissionalizantes-tem-cota-para-alunos-da-rede-privada.shtml

CEARÁ. SECRETARIA DA EDUCAÇÃO (2014), Relatório de gestão: o pensar e o fazer da educação profissional no Ceará 2008 - 2014. Fortaleza, SEDUC-CE.

COSTA, Márcio (2008), "Prestígio e hierarquia escolar: estudo de caso sobre diferenças entre escolas em uma rede municipal". Revista Brasileira de Educação, v. 13, n. 39, pp. 455-469.

COSTA, Márcio; CAMARGO, Paulo de (2010), "Lógica de quase-mercado". Revista Educação, n. 153 [Consult. 18-06-2015]. Disponível em http://revistaeducacao.uol.com.br/formacaodocente/153/artigo234697-1.asp

COSTA, Márcio da; KOSLINSKI, Mariane Campelo (2011), "Quase-mercado oculto: disputa por escolas 'comuns' no Rio de Janeiro”. Cadernos de Pesquisa, v. 41, n. 142, pp. 245-266.

DUBET, François (1996). Sociologia da Experiência. Lisboa, Instituto Piaget.

DUBET, François; MARTUCELLI, Danilo (1997), “A socialização e a formação escolar”. Lua Nova, n. 40, pp. $242-328$.

HAECHT, Anne Van (2008), Sociologia da Educação: a escola posta à prova. 3. ed. Porto Alegre, Artmed.

LAHIRE, Bernard (1997), Sucesso escolar nos meios populares: as razões do improvável. São Paulo, Ática.

LAHIRE, Bernard (2002), Homem plural: os determinantes da ação. Petrópolis, Vozes.

LAHIRE, Bernard (2004), Retratos sociológicos: disposições e variações individuais. Porto Alegre, Artmed.

LAHIRE, Bernard (2006), A cultura dos indivíduos. Porto Alegre, Artmed.

LAHIRE, Bernard (2015), "A fabricação social dos indivíduos: quadros, modalidades, tempos e efeitos de socialização". Educação e Pesquisa, v. 41, pp. 1393-1404, dez. 
LAHIRE, Bernard; CHÂTEAUNEUF-MALCLÈS, Anne (2016), "Entretien avec Bernard Lahire: la sociologie n'incarne pas une 'culture de l'excuse". [S.1]: SES-ENS [Consult. 23-08-2018]. Disponível em http://ses.ens-lyon.fr/articles/entretien-avec-bernard-lahire-la-sociologie-n-incarnepas-une-culture-de-1-excuse--294371

LAREAU, Annette (2007), "A desigualdade invisível: o papel da classe social na criação dos filhos em famílias negras e brancas”. Educação em Revista. Belo Horizonte, n. 46, pp. 13-82.

LAREAU, Annette (2011). Unequal childhoods: class, race and family life. 2. ed. Berkeley, University of California Press.

LAREAU, Annette; EVANS, Shani Adia; YEE, April (2016), "The Rules of the Game and the Uncertain Transmission of Advantage: middle-class parents' search for an urban kindergarten". Sociology of Education, v. 89, n. 4, pp. 279-299.

NEVES, Clarissa Eckert Baeta (2013), "Trajetórias escolares, famílias e políticas de inclusão social no Ensino Superior brasileiro”, in. G. Romanelli; M. A. Noguiera; N. Zago (Orgs.). Família \& escola: novas perspectivas de análise. Petrópolis, Vozes. pp. 278-311.

NOGUEIRA, Cláudio Marques Martins (2004), Dilemas na análise sociológica de um momento crucial das trajetórias escolares: o processo de escolha do curso superior. Tese (Doutorado em Educação). PPGE, FACED-UFMG, Belo Horizonte. 185 p.

NOGUEIRA, Maria Alice (2005), "A relação família-escola na contemporaneidade: fenômeno social/interrogações sociológicas”. Análise Social, v. 11, n. 176, pp. 563-578 [Consult. 12-012014]. Disponível em http://www.scielo.gpeari.mctes.pt/scielo.php?script=sci_arttext\&pid=S0003$25732005000400005 \& \mathrm{nrm}=$ iso

NOGUEIRA, Maria Alice (2011), “A categoria 'família' na pesquisa em Sociologia da Educação: notas preliminares sobre um processo de desenvolvimento". Revista Inter-Legere, n. 9, pp. 156-166 [Consult. 21-01-2017]. Disponível em https://periodicos.ufrn.br/interlegere/article/view/4410

NOGUEIRA, Maria Alice (2013), "No fio da navalha - A (nova) classe média brasileira e sua opção pela escola particular". in G. Romanelli; M. A. Noguiera; N. Zago (Orgs.). Família \& escola: novas perspectivas de análise. Petrópolis, Vozes, pp. 109-130.

ROSISTOLATO, Rodrigo (2015), "Choice and access to the best schools of Rio de Janeiro: a rite of passage". Vibrant, v. 12, n. 2, pp. 380-416.

SANTOS, Harlon Romariz Rabelo (2017), Configuração e mobilização familiar nas Escolas Estaduais de Educação Profissional: entre disposições, escolhas e motivações. 2017. Dissertação (Mestrado em Sociologia). PPGS, DCS-UFC, Fortaleza. 188 p.

ZANTEN, Agnès Van (2007), "Reflexividad y elección de la escuela por los padres de la clase media en Francia”. Revista de Antropología Social, v. 16, pp. 245-278. 


\begin{abstract}
Four cases of parental involvement are analyzed here, surveyed in different public schools in Ceará. Case studies from high school students and their parents, from two of the State Schools of Vocational Education (EEEP), in 2016. Analysis is made through the dispositional sociology of Bernard Lahire, which focuses on the actions and practices of individuals to from the notion of dispositional schemas, contexts and logic of action. Perspective facing the tension between the corporate past and the present of action. Data and analysis allow us to recognize external contextual frameworks that mobilize or inhibit dispositional schemes embodied, specifically in relation to greater or lesser parental involvement among parents from different socioeconomic and cultural capitals.
\end{abstract}

Keywords: Parental involvement; school choice; differentiated schools; sociology of education.

\title{
Resumen
}

Se analizan aquí cuatro casos de participación parental, investigados en escuelas públicas diferenciadas en el Ceará. Casos de los estudiantes de enseñanza media y sus padres, de dos de las Escuelas Estaduales de Educación Profesional (EEEP), en el año 2016. El análisis se hace por medio de la sociología disposicionalista de Bernard Lahire, que se centra en las acciones y prácticas de los individuos a la sociedad a partir de la noción de esquemas disposicionais, contextos y lógicas de acción. Perspectiva que enfrenta la tensión entre el pasado incorporado y el presente de la acción. Los datos y el análisis permiten reconocer cuadros contextuales externos que movilizan o inhiben esquemas disposicionais incorporados, específicamente, en relación al mayor o menor envolvimiento parental entre padres de diferentes capitales socioeconómicos y culturales.

Palabras clave: Participación parental; elección escolar; escuelas diferenciadas; sociología de la educación. 